\title{
A study on the optimization strategies for the service trade structure of Guangdong-Hong Kong-Macao Greater Bay Area
}

\author{
Wenyong Li $^{1, *}$, Xueyu Zhang ${ }^{1}$, Bing'e Tang ${ }^{1}$ \\ ${ }^{1}$ Huali College Guangdong University of Technology, Guagzhou, China
}

\begin{abstract}
The construction of urban agglomerations and integration of regional economics have become the new trends in Chinese economic development. The economy of Guangdong-Hong Kong-Macao Greater Bay Area plays a significant role in driving regional development and stimulating technological innovation. In this paper, through study on the current situation of trade in service in Guangdong-Hong Kong-Macao Greater Bay Area, the reasons for the improper trade structure are concluded. Through data and case analysis, the factors affecting service trade structure are located. The results of case analysis can offer some useful and viable recommendations for the optimization of service trade structure, which can facilitate the industrial transformation and upgrading in Guangdong-Hong Kong-Macao Greater Bay Area as well as give a fresh impetus to economic growth.
\end{abstract}

\section{Introduction}

In 2015, the concept of the Guangdong-Hong KongMacao Greater Bay Area was formally proposed, which gradually attracted great attention and led to heated discussions among domestic and international academic circles, political circles, business circles and ordinary people. Whether the structure of service trade in the Guangdong-Hong Kong-Macao Greater Bay Area is reasonable has become a decisive factor affecting the international competitiveness of the Guangdong-Hong Kong-Macao Greater Bay Area. Therefore, a comprehensive analysis of the factors influencing the optimization of the service trade structure in the Guangdong-Hong Kong-Macao Greater Bay Area, and a research on its optimization strategies will improve the international competitiveness of the Guangdong-Hong Kong-Macao Greater Bay Area and accelerate its industrial transformation and upgrading, which will contribute to economic growth and is thus of great significance..

The Guangdong-Hong Kong-Macao Greater Bay Area has a total area of 56,000 square kilometers, including Hong Kong Special Administrative Region, Macau Special Administrative Region, Guangzhou, Shenzhen, Zhuhai, Foshan, Huizhou, Dongguan, Zhongshan, Jiangmen and Zhaoqing. At the end of 2017, the total population was approximately 70 million. It is one of the regions with the highest degree of openness and the strongest economic vitality in China.

\section{Theoretical Measurement of Optimizing the Structure of Service Trade}

\subsection{Trade Competitive Advantage Index}

The trade competition index refers to the ratio of a certain product in a country or region to the total trade of that type of product. It is often used to measure the trade competitiveness of this type of product. The calculation formula of the trade competition index is as follows:

$$
A=(X i-M i) /(X i+M i)
$$

$\mathrm{Xi}$ and Mi respectively represent the export value and import value of the service trade product in the country or region. From the formula, we can deduce that the range of $A$ is $(-1,1)$. When $-1<A<0$, it means that the service trade product has a trade deficit, and the trade competitiveness of the product is weaker. The closer the service trade competition index is -1 , indicating that the service trade competitiveness of the service product is weaker; when $0<\mathrm{A}<1$, otherwise, it indicates that there is a surplus and the service trade competitiveness of the product is stronger. The closer A is to 1 , the service trade of the product The stronger the trade competitiveness.

\subsection{Revealed Comparative Advantage Index}

The revealed comparative advantage index refers to the ratio of the export value of a certain service product of a certain country or region to the total service trade export value of the country or region and the ratio of the world

\footnotetext{
*Corresponding author: 747317364@qq.com
} 
export value of the product to the world total service trade export value. to measure the competitiveness of this country or region in the international market through the calculation of comparative advantage. We use B to represent the revealed comparative advantage index, and the formula can be expressed as:

$$
B=(X i / X) /(X i w / X w)
$$

$\mathrm{Xi}$ and $\mathrm{X}$ respectively represent the export value of the product in the country or region and the total export value of the country or region. Xiw and $\mathrm{Xw}$ respectively represent the export value of the product in the world and the total export value of the world. It is generally believed that when $\mathrm{B}>2.5$ in a country or region, the industry in that country or region has strong international competitiveness; when $1.25<\mathrm{B}<2.5$, the country or region has strong international competitiveness; When $0.8<\mathrm{B}<1.25$, the country or region has strong international competitiveness; when $\mathrm{B}<0.8$, the international competitiveness of the product in the country or region is relatively weak.

\subsection{Relative Index of Service Trade Structure Optimization}

The relative index of service trade structure optimization refers to the ratio of the export value of modern service trade to the export value of traditional service trade in a certain country or region in a certain period of time. It is often used to measure the degree and level of service trade structure optimization. In this paper, $\mathrm{C}$ is used to represent the relative index of service trade structure optimization, and the calculation formula can be expressed as:

$$
C=X m / X t
$$

$\mathrm{Xm}$ and $\mathrm{Xt}$ respectively represent the export value of modern service trade and the export value of traditional service trade in a certain country or region in a certain period of time. Generally speaking, the larger the $C$, the better the service trade structure of the country or region; on the contrary, the smaller the $\mathrm{C}$, the worse and the more unreasonable the service trade structure of the country or region.

\section{Development status of service trade in Guangdong-Hong Kong-Macao Greater Bay Area}

\subsection{Obvious advantages in location characteristics}

The advantageous geographical location, excellent seaport and long coastline are the huge advantages of the Hong Kong-Macao Greater Bay Area for the development of trade. At the same time, the Greater Bay Area is the developed economic zone closest to the South China Sea and has unique advantages in natural resources. Since ancient times, the Guangdong, Hong Kong and Macao regions have been China's main foreign trade cities. In the
21 st century, it has been designated by the state as the starting point of the two maritime silk roads. As the region is close to the world's first golden channel, is the confluence point of the Indian Ocean and the Pacific Ocean, and is an important transportation channel in the Asia-Pacific region, it can deeply participate in the Maritime Silk Road and vigorously develop import and export trade through the Maritime Silk Road to promote rapid economic development. Guangzhou is the closest geographical connection point to the Silk Road, with a well-developed infrastructure and advanced transportation network. It is in the forefront of the country in the fields of finance, electronics, energy, and communications. Compared with other regions in China, it has a huge influence in the international arena. As a free trade zone, Hong Kong and Macao have a great understanding of international economics and trade rules, and also play an important economic role in the development of domestic and foreign trade.

\subsection{The scale of service trade ranks first in the country}

In 2016, the Pearl River Delta's comprehensive foreign trade services, tourism and shopping exports, cross-border e-commerce and other new service industries developed rapidly. The total import and export volume of the service industry reached 978.69 billion yuan, an increase of $19.3 \%$ year-on-year, accounting for $18.3 \%$ of the country's total, making it the first to rank No.1 nationwide; service trade accounted for $13.4 \%$ of foreign trade (trade in goods and trade in services), of which service exports were 384.73 billion yuan, an increase of $0.9 \%$ year-on-year; service imports were 593.96 billion yuan, an increase of $35.2 \%$ year-on-year. The construction of the Guangdong Pilot Free Trade Zone has been accelerated, and 76,000 new enterprises have been established in the Pilot Free Trade Zone. The mid-term goals of the Guangdong-Hong Kong and Guangdong-Macao Cooperation Framework Agreement have been basically completed. The liberalization of service trade in Guangdong, Hong Kong and Macao has achieved remarkable results.

\subsection{Service trade import category list}

The import category of service trade in the Pearl River Delta is relatively single. Currently, there are a wide range of international service trade types. In addition to traditional service trade types such as transportation, tourism, and construction, many new types of service trade, such as finance and insurance, have sprung up just like bamboo shoots. The service trade in the Pearl River Delta accounts for a large proportion of the traditional service trade types, and there is still a lot of room for the import of emerging service trade types, as shown in Table 1. 
Table1. Imports of emerging service trade in the Pearl River Delta in recent years

\begin{tabular}{|c|c|c|c|c|}
\hline & $\mathbf{2 0 1 8}$ & $\mathbf{2 0 1 7}$ & $\mathbf{2 0 1 6}$ & $\mathbf{2 0 1 5}$ \\
\hline Travel & $53.3 \%$ & $55.7 \%$ & $65.6 \%$ & $58.1 \%$ \\
\hline Transport & $20.5 \%$ & $19.3 \%$ & $13.9 \%$ & $20.1 \%$ \\
\hline $\begin{array}{c}\text { Government service } \\
\text { Other business services }\end{array}$ & $0.9 \%$ & $0.8 \%$ & - & - \\
\hline $\begin{array}{c}\text { Maintenance and repair } \\
\text { services }\end{array}$ & $0.5 \%$ & $3.2 \%$ & $3.2 \%$ & $3.5 \%$ \\
\hline $\begin{array}{c}\text { Personal, cultural and } \\
\text { entertainment services }\end{array}$ & $0.6 \%$ & $0.5 \%$ & - & $0.4 \%$ \\
\hline $\begin{array}{c}\text { Intellectual property usage } \\
\text { fee }\end{array}$ & $6.9 \%$ & $8.4 \%$ & $7.9 \%$ & $5 \%$ \\
\hline $\begin{array}{c}\text { Telecommunications, } \\
\text { computer and information } \\
\text { services }\end{array}$ & $4.4 \%$ & $4.0 \%$ & $2.1 \%$ & $2.5 \%$ \\
\hline $\begin{array}{c}\text { Financial Services } \\
\text { Professional management } \\
\text { and consulting }\end{array}$ & $0.4 \%$ & $0.3 \%$ & $0.3 \%$ & $0.7 \%$ \\
\hline $\begin{array}{c}\text { Technical Services } \\
\text { Bnsurance service }\end{array}$ & $2.2 \%$ & $2.1 \%$ & $2.3 \%$ & $1.7 \%$ \\
\hline & $1.6 \%$ & $1.8 \%$ & $1.7 \%$ & $2.3 \%$ \\
\hline
\end{tabular}

\section{Countermeasures and Suggestions for Optimizing the Structure of Service Trade in the Guangdong-Hong Kong- Macao Greater Bay Area}

\subsection{Increase support for modern service trade}

On the premise of maintaining the advantages of traditional industries, the government vigorously promotes and encourages the development of emerging service industries, such as computer information services, financial insurance services, service outsourcing and other industries, including increasing financial support for these industries and improving transportation and road facilities , Communication networks, information technology and other infrastructures, give full play to the role of physical capital accumulation in promoting and optimizing the structure of service trade. The government can also promulgate policies that are conducive to the modern service trade industry, actively work to create a fair competitive environment, promote the vigorous development of emerging service industries in Jiangsu Province, expand the areas of service trade in the Bay Area, and change the prevailing situation of traditional service trade. to improve the structure of service trade, and to be in line with the international service trade dominated by emerging service trade.

\subsection{Strengthen industrial technology development and product innovation}

In order to optimize the structure of service trade and make the Guangdong-Hong Kong-Macao Greater Bay Area service trade in line with international standards, enterprises should first upgrade their products, and products are the core of trade. And this article proposes to improve the technical content of products and improve product quality. Therefore, enterprises should actively respond to the government's call, establish an awareness of innovation, focus on the role of innovation and technology in the process of enterprise growth and development, actively recruit and train innovative talents, and promote the innovative development of the entire industry and industry. We must also establish patent awareness and brand awareness, continue to build our own patent advantages and brand advantages, focus on the development of technology, support higher-quality service products with technology, and attract more consumers with excellent brands and high-level quality. Through technological innovation and brand promotion, the market competitiveness of service trade in the Guangdong-Hong Kong-Macao Greater Bay Area will be improved, so as to provide a firm foundation for the development of the service trade industry.as shown in Table 2.

Table2. Services trade in the cities and the two wings of the Pearl River Delta

\begin{tabular}{|c|c|c|c|c|c|}
\hline \multirow{2}{*}{ City } & \multicolumn{5}{|c|}{ Year } \\
\cline { 2 - 6 } & $\mathbf{2 0 1 5}$ & $\mathbf{2 0 1 6}$ & $\mathbf{2 0 1 7}$ & $\mathbf{2 0 1 8}$ & $\mathbf{2 0 1 9}$ \\
\hline \multirow{2}{*}{ Guangzhou } & 12147.49 & 13653.19 & 15271.69 & 14663.32 & 16923.22 \\
\hline Shenzhen & 10288.28 & 11760.77 & 13140.32 & 15236.99 & 16390.01 \\
\hline Zhuhai & 973.00 & 1107.32 & 1339.17 & 1711.86 & 1849.79 \\
\hline Foshan & 3028.00 & 3339.28 & 3840.22 & 4168.66 & 4549.48 \\
\hline Huizhou & 1277.17 & 1425.87 & 1642.50 & 1705.00 & 1802.79 \\
\hline Dongguan & 3332.00 & 3646.02 & 3896.01 & 3831.87 & 4092.52 \\
\hline Zhongshan & 1310.85 & 1457.91 & 1649.71 & 1451.32 & 1516.68 \\
\hline Jiangmen & 903.38 & 1014.15 & 1169.56 & 1470.76 & 1539.87 \\
\hline Zhaoqing & 650.84 & 683.61 & 863.50 & 886.79 & 937.23 \\
\hline
\end{tabular}




\subsection{Increase public support}

First of all, the public must get rid of prejudice against domestic and local service products, abandon the qualitative thinking that foreign products are of higher quality than domestic products, treat all products uniformly, and give all products equal opportunities for competition. Secondly, we must change traditional consumer concepts, focus more on emerging service products, such as financial and insurance products, increase consumer demand in modern service industries, and improve traditional service trade and modern services in Jiangsu Province. The status quo of unbalanced trade development. Finally, it is necessary to vigorously support the development of local service industries, consume local service products, expand service trade exports, reduce imports, convert the phenomenon of increasing service trade deficits, and optimize the structure of service trade.

\section{Problems in the development of service trade in the Guangdong-Hong Kong-Macao Greater Bay Area}

\subsection{The development of service trade lags behind}

There is a clear gap between the development level of the service industry in the Guangdong-Hong Kong-Macao Greater Bay Area and the other three major bay areas in the world. Historical data shows that the economic structure of the Greater Bay Area tends to transform from a port industrial economy to an innovative economy in the service industry. For example, in 2018, the service industry in Tokyo area accounted for $88.3 \%$, California area accounted for $82.8 \%$, and New York area accounted for $89.4 \%$. But at present, the Guangdong-Hong KongMacao Greater Bay Area is still dominated by port industrial economy, and the service industry is not yet developed.

\subsection{The development of service trade is seriously unbalanced}

After the Guangdong-Hong Kong-Macao Greater Bay Area achieves physical spatial connectivity through infrastructure construction such as the Guangdong-Hong Kong-Macao Bridge, the current focus and difficulty of the optimization of the service trade structure in the Greater Bay Area lies in the realization of structural optimization through service trade. However, due to the degree of economic development, as well as the difference in economic pillar industries and corresponding government policies, there is a serious imbalance in the development of service trade in Guangdong, Hong Kong and Macao, especially the development gap between the central and two wings of the Pearl River Delta.

\section{Conclusion}

With the acceleration of China's internationalization process, a higher level of opening to the outside world will face more and more complex problems. Optimizing the structure of service trade is an important part of the internationalization process. Whether the structure of service trade in the Guangdong-Hong Kong-Macao Greater Bay Area is reasonable has become a decisive factor affecting its international competitiveness. Therefore, this paper analyzes the influencing factors of the optimization of the service trade structure in the Guangdong-Hong Kong-Macao Greater Bay Area and studies its optimization strategies, which will provide new impetus improving the international competitiveness of the service trade in the Guangdong-Hong Kong-Macao Greater Bay Area, accelerate its industrial transformation and upgrading as well as drive its economic growth.

\section{Acknowledgment}

This research was financially supported by the Key Research Platforms and Scientific Research Projects of Guangdong Province in 2018 (Young Innovative Talents) (Grant NO. 2018WQNCX261) and Supported by the 2019 school-level scientific research project of Huali College Guangdong University of Technology (Grant NO. HLKY-2019-SK-02).

\section{References}

1. Li Xiaoying. An Empirical Analysis of the Main Influencing Factors of the Changes in the Service Trade Structure in the Pearl River Delta[J]. Journal of Hubei University of Science and Technology, 2014, 34(09): 19-20.

2. Yang Hongai, Yin Weihua. Research on the Influencing Factors and Strategies of China's Service Trade Structure Optimization[J]. Business Economics Research, 2019(22): 153-156

3. Gong Huajing. Research on the Problems Existing in the Structure of my country's Service Trade[J]. Modern Business, 2017(27): 44-45

4. Xiao Liqiu. Research on the optimization path of service trade structure[J]. Business Economics Research, 2016(14):119-122

5. Lu Zhaofeng, Wang Daohua. Structural changes, influencing factors and optimization countermeasures of China's service trade[J]. Business Economics Research, 2015(29): 19-20. 